\title{
THE IMPACT OF LEADERSHIP AND CULUTRE OF ORGANIZATION TO EMOTIONAL INTELLIGENCE BY TRAINING OF PT. XYZ
}

\author{
P-ISSN: 2089-4341 | E-ISSN: 2655-9633 \\ Link: https://uia.e-journal.id/akademika/article/view/751 \\ DOI: 10.34005/akademika.v9i01.751 \\ Bahyudi \\ bahyudi@gmail.com \\ Manajemen Universitas Mercubuana \\ Indonesia
Tjiptogoro Dinarjo Soehari
tjiptogd@yahoo.com
Indonesia \\ Manajemen Universitas Mercubuana
}

\begin{abstract}
Modern retail business competition is increasingly fierce today, making business competitors continue to improve services and development in order to compete in the current era, one of which is $P T$. $X Y Z$, which is engaged in supermarket retailing, continues to develop its chain of stores in several regions in Indonesia and improve the quality of its leaders. This study discusses and analyzes the leadership and culture of emotional intelligence that is by training. The study was taken from several employees of PT. XYZ during August, September and October. The sampling method used was purposive sampling, from a population of 161 PT. XYZ meets the criteria for being a sample. The analytical method used in this study is Structural Equitional Modeling with Lisrel. The results showed that leadership had a positive and significant effect on training. The effect of training on emotional intelligence has a positive and significant effect on emotional intelligence. The influence of organizational culture on emotional intelligence also has a positive and significant effect on emotional intelligence. Organizational culture is the most influential variable on emotional intelligence.
\end{abstract}

Keywords : Leadership, Culture of Organization, Emotional Intelligence and Training

\begin{abstract}
Abstrak: Persaingan bisnis ritel modern semakin sengit dewasa ini, membuat para pesaing bisnis terus meningkatkan layanan dan pengembangan agar dapat bersaing di era saat ini, salah satunya adalah PT. XYZ, yang bergerak di bidang ritel supermarket, terus mengembangkan rantai toko di beberapa daerah di Indonesia dan meningkatkan kualitas para pemimpinnya. Penelitian ini membahas dan menganalisis kepemimpinan dan budaya kecerdasan emosional yaitu dengan pelatihan. Penelitian ini diambil dari beberapa karyawan PT. XYZ selama Agustus, September, dan Oktober. Metode pengambilan sampel yang digunakan adalah purposive sampling, dari populasi $161 \mathrm{PT}$. XYZ memenuhi kriteria untuk menjadi sampel. Metode analisis yang digunakan dalam penelitian ini adalah Structural Equitional Modeling with Lisrel. Hasil penelitian menunjukkan bahwa kepemimpinan berpengaruh positif dan signifikan terhadap pelatihan. Efek pelatihan pada kecerdasan emosional memiliki efek positif dan signifikan pada kecerdasan emosional. Pengaruh budaya organisasi terhadap kecerdasan emosi juga memiliki pengaruh positif dan signifikan terhadap kecerdasan emosional. Budaya organisasi adalah variabel yang paling berpengaruh pada kecerdasan emosi.
\end{abstract}

Kata kunci: Kepemimpinan, Budaya Organisasi, Kecerdasan Emosi, Pelatihan 


\section{PENDAHULUAN}

Kondisi dunia ritel saat ini kini menjadi sorotan setelah beberapa perusahaan yang bergerak di dunia ritel menutup gerainya baik ritel supermarket maupun ritel fasion dan beberapa tahun yang lalu juga salah satu perusahaan ritel supermarket yang cukup nesar menutup semua gerainya yang ada di Indonesia. Beberapa perusahaan ritel yang ada melihat ini adalah persaingan yang semakin ketat. Persaingan itu bukan semata antara toko supermarket dengan toko lain (offline), tetapi juga dengan penjualan dalam jaringan (online).

Semakin ketatnya persaingan dalam dunia bisnis dan berkembangnya kemajuan teknologi informasi membuat perusahaan PT. $\mathrm{XYZ}$ yang bergerak dibidang ritel supermarket untuk terus melakukan ekspansi guna menjaga keberlangsungan perusahaan dan dalam memenuhi target management, baik dengan memperluas jaringan gerai maupun dengan mempercanggih teknologi yang digunakan. Proses perkembangannya PT. XYZ harus terus diimbangi dengan menciptakan sumber daya manusia yang unggul dalam persaingan saat ini, terutama dilevel pemimpin, karena para pemimpin inilah yang nanti akan memandu dan menjaga tim nya untuk mencapai tujuan organisasi.

Berdasarkan data tahun 2019, penerapan guideline leadership yang ada pada perusahaan tidak semuanya bagus, terlihat dari beberapa kriteria guideline hasil perhitungan tahun 2019 yakni, menyamapaikan tugas kepada bawahan $72 \%$, memberikan umpan balik positif sebesare $36 \%$ (rendah), memberikan umpan balik korektif kepada bawahan $54 \%$ (cukup rendah), menangani permasalahan kerja dan memeberikan informasi kepada atasan $81 \%$. Dalam proses pembentukankepemimpinan dilakukan training mandatory untuk tiap level jabatan yang diberikan, untuk level staff sebanyak 42 jam, level quality control sebanyak 70 jam, assistant supervisor sebanyak 154 jam, supervisor sebanyak 154 jam, assistant store manager sebanyak 238 jam dan sotre manager sebanyak 280 jam. Hasil target guideline leadership tidak tercapai sehingga penelitian meningkatkan kepemimpinan melalui pelatihan. Dalam rangka memperoleh faktor penelitan telah dilakukan individu Depth interview (IDI) terhadap 6 reponden dan diperoleh faktor-faktor kepemimpinan, budaya organisasi, pelatihan dan kecerdasan emosi yang selanjutnya dijadikan variabel penelitian.

Menurut Hersey dan Blanchard (2018:5), pimpinan adalah seseorang yang dapat mempengaruhi orang lain atau kelompok untuk melakukan unjuk kerja maksimum yang telah ditetapkan sesuai dengan tujuan organisasi. Organisasi akan berjalan dengan baik jika pimpinan mempunyai kecakapan dalam bidangnya, dan setiap pimpinan mempunyai keterampilan yang berbeda, seperti keterampilan teknis, 
manusiawi dan konseptual. Kepemimpinan menurut Effendi (2017:13) kepmimpinan adalah cara seorang pemimpin melaksanakan kegitannya dalam upaya membimbing, memandu, mengarahkan, dan mengontrol pikiran, perasaan, atau perilaku sesorang atau sejumlah orang untuk mencapai tujuan. Abdul Rizal dan Farida Elmi (2017) dalam jurnal gaya kepmimpinan transformasional, disiplin kerja dan penempatan kerja terhadap koinerja, gaya kepemimpinan mendasarkan diri pada prisnip pertukana kepemimpinan berdasarkan penegembangan bawahan.

Menurut Robbins \& Judge (2015), menyatakan bahwa peran atau fungsi budaya di dalam suatu organisasi, yaitu, Sebagai tapal batas yang membedakan secara jelas suatu organisasi dengan organisasi lain, memberikan rasa identitas bagi anggota-anggota organisasi, memudahkan penerusan komitmen hingga mencapai batasan yang lebih, luas dari pada kepentingan individu, mendorong stabilitas system social, merupakan perekat social yang membantu mempersatukan organisasi,membentuk rasa dan kendali yang memberikan panduan dan membentuk sikap serta perilaku karyawan. Susanto (2014:36) budaya organisasi atau perusahaan adalah nilai-nilai yang menjadi pegangan sumber daya manusia dalam menjalankan kewajiban dan perilakunya di dalam organisasi. Nilai-nilai tersebut yang akan memberi jawaban apakah suatu tindakan benar atau salah dan apakah suatu perilaku dianjurkan atau tidak sehingga berfungsi sebagai landasan untuk berperilaku. Menurut (Naraya 2017 dalam Asih Andayani 2019) budaya organisasi adalah tradisi atau kepercayaan organisasi yang ditentukan dari organisasi lain dan memberikan kehidupan tertentu atas persetujuan dan struktur organisasi tersebut.

Menurut Robbins \& Judge (2015:212), menyatakan bahwa peran atau fungsi budaya di dalam suatu organisasi, yaitu: 1) Sebagai tapal batas yang membedakan secara jelas suatu organisasi dengan organisasi lain 2) Memberikan rasa identitas bagi anggota-anggota organisasi. 3) Memudahkan penerusan komitmen hingga mencapai batasan yang lebih Luas daripada kepentingan individu. 5) Mendorong stabilitas system social, merupakan perekat social yang membantu mempersatukan organisasi. 6) Membentuk rasa dan kendali yang memberikan panduan dan membentuk sikap serta perilaku karyawan.

Menurut Widodo (2015:82), pelatihan merupakan serangkaian aktivitas individu dalam meningkatkan keahlian dan pengetahuan secara sistematis sehingga mampu memiliki kinerja yang profesional di bidangnya. Pelatihan adalah proses pembelajaran yang memungkinkan pegawai melaksanakan pekerjaan yang sekarang sesuai dengan standar. Menurut Zainal et al. (2014:164), pelatihan adalah suatu proses dengan cara sistematis untuk mengubah tingkah laku karyawan untuk mencapai tujuan organisasi. Pelatihan mempunyai beberapa manfaat yang dikemukakan oleh Veithzal et al (2014:167) yaitu: 1) Manfaat untuk 
karyawan a) membantu karayawan dalam membuat keputusan dan dalam memecahkan masalah yang efektif. b) Membantu mendorong dan mencapai pengembangan diri dan rasa percaya diri. c) Membantu karyawan mengatasi stres, tekanan, frustasi dan konflik dalam pekerjaan. 2) Manfaat untuk perusahaan a) Memperbaiki moral SDM. b) Membantu karyawan untuk mengetahui tujuan perusahaan. c) Membantu menciptakan image perusahaan yang lebih baik. d) Meningkatkan hubungan antara atasan dan bawahan. e) Membantu meningkatkan komunikasi organisasi. f) Membantu menangani konflik sehingga terhindar dari stress dan tekanan kerja. Maabut (2016) Penelitian ini merupakan penelitian di bidang manajemen sumber daya manusia yaitu aplikasi dari metode ilmiah dalam pencarian kebenaran tentang fenomena manajemen sumber daya manusia.

Menurut Bar-on dalam Dewi ayu (2018:3), merumuskan kecerdasan emosional sebagai kemampuan yang mempengaruhi proses penyesuaian psikologis, dengan mengenal diri dan orang lain untuk mampu mengekspresikan diri serta menjalin hubungan yang harmonis dengan orang lain, sehingga individu mampu mengatasi tuntutan, tantangan dan tekanan sehari-hari.

Menurut Daniel Goleman dalam Farah (2018), kecerdasan emosional yaitu kemampuan untuk memotivasi diri sendiri dan bertahan menghadapi frustrasi, mengendalikan dorongan hati dan tidak melebihlebihkan kesenangan, mengatur suasana hati dan menjaga agar beban stress tidak melumpuhkan kemampuan berpikir, berempati dan berdoa. Berdasarkan berbagai definisi kecerdasan emosional dan pendapat para ahli dapat disimpulkan bahwa kecerdasan emosional adalah ilmu mengenai keterampilan seseorang untuk memahami emosi yang dialami dirinya dan juga pada orang lain sehingga dapat menggunakannya untuk mendapatkan hasil yang diinginkan dari diri sendiri maupun orang lain.

Menurut Agus Efendi dalam Diva (2018) kecerdasan emosi adalah jenis kecerdasan yang fokusnya memahami, mengenali, merasakan, mengelola, dan memimpin perasaan diri sendiri dan orang lain serta mengaplikasikannya dalam kehidupan pribadi dan sosial. Menurut Bar-on dalam (Dewi 2018), merumuskan kecerdasan emosional sebagai kemampuan yang mempengaruhi proses penyesuaian psikologis, dengan mengenal diri dan orang lain untuk mampu mengekspresikan diri serta menjalin hubungan yang harmonis dengan orang lain, sehingga individu mampu mengatasi tuntutan, tantangan dan tekanan sehari-hari.

\section{METODE}

Metode dalam penelitian ini menggunakan metode kuantitatif, dengan jenis penelitian assosiatif, dan data kuantitatif dengan menggunakan kuesioner yang bersifat cross sectional. Pengambilan 
sampling yang di ambil pada penelitian ini dengan menggunakan purposive sampling yakni responden dengan beberapa kriteria pada karyawan PT. XYZ yakni posisi sebagai assistant supervisor dan supervisor sebanyak 161 sampel yang tersebar diseluruh wilayah Indonesia, metode pengumpulan data menggunakan kuesioner dengan bobot nilai menggunakan skala likert, pengolahan data dilakukan dengan SEM (Structural Equations Modeling) menggunakan software Lisrel.

\section{HASIL}

Validitas konstruk dapat dilakukan dengan melihat nilai loading factor masing-masing indikator konstruk. Dalam penelitian ini indikator dikatakan valid jika nilai loading factor $>0.4$, sedangkan uji reliabilitas konstruk dilakukan dengan menghitung nilai AVE dan CR konstruk, konstruk dinyatakan reliabel jika AVE model $>0.5$ dan model $\mathrm{CR}>0.7$.

Hasil analisis data disusun secara deskriptif dari setiap variabel yang diperoleh. Penelitian ini memperoleh 161 responden karayawan PT. XYZ. Berdasarkan hasil, ada 101 karyawan pria dengan persentase $63 \%$ dan karyawan wanita sebanyak $63 \%$ dan karyawan wanita sebanyak 60 dengan persentase $37 \%$. Berdasarkan usia responden karyawan dengan usia $<25$ tahun sebanyak 45 orang dengan persentase $28 \%$, usia antara 26 - 35 tahun sebanyak 86 dengan persentase $53 \%$, usia $36 \mathrm{~cd}-45$ tahun sebanyak 29 dengan persentase $18 \%$ dan usia $46-55$ tahun sebanyak 1 orang dengan persentase sebesear $0.6 \%$. Berdasarkan tingkat pendidikan responden dengan tingkat pendidikan SMA sebanyak 97 dengan persentase $60 \%$, Diploma sebanyak 30 orang dengan persentase $19 \%$, S1 sebanyak 32 orang dengan persentase $20 \%$, dan S2 sebanyak 2 orang dengan persentase $1 \%$

Gambar 1. Pengujian Model Struktural 


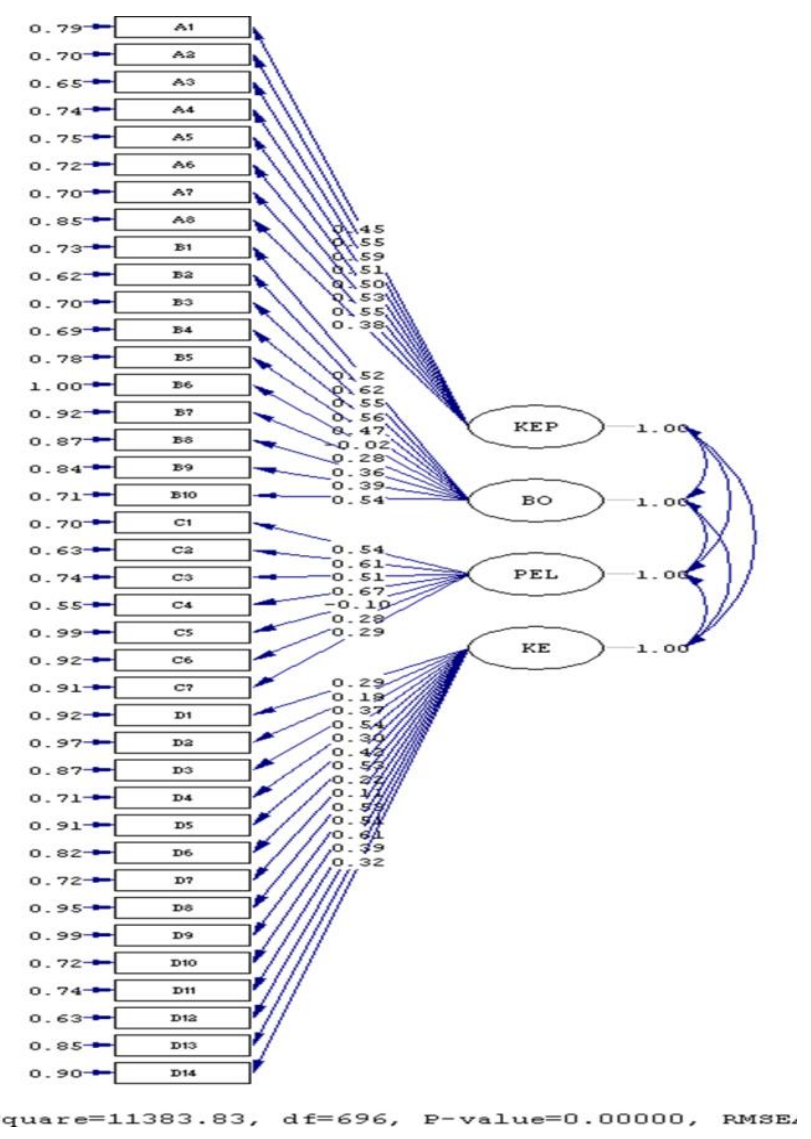

Berdasarkan hasil output completely standardized diperoleh koefisen lamda-y $(\lambda y)$ seluruhnya bernilai lebih dari 0.6 maka dapat disimpulkan bahwa indicator variabel manifest $Y$ seluruhnya valid. Sementara untuk variabel manifest $X$ pada variabel kepemimpinan ada satu koefisien yang nilainya kurang dari 0.4 atau 0.7 yakni $A 8$ sedangkan koefisien A1, A2, A3, A4, A5, A6, A7 seluruhnya valid. Khusus untuk A8 karena tidak valid sebaiknya di drop jangan digunakan sebagai variabel laten kepemimpinan. Variabel manifest $\mathrm{X}$ pada budaya organisasi ada beberapa koefisien yang kurang dari 0.4 atau 0.7 yakni B5, B6, B7, B8, B9 sedangkan koefisien B1, B2, B3, B4, B10 seluruhnya valid. Khusus untuk variabel manifest B5, B6, B7, B8, B9 sebaiknya didrop jangan digunakan lagi sebagai variabel laten budaya organisasi. variabel manifest $X$ pada pelatihan ada beberapa koefisine yang kurang dari 0.4 yakni C5, C6, C7 sedangkan koefisien C1, C2, C3, C4 seluruhnya valid. Khusus untuk C5, C6, C7 sebaiknya didrop sebaiknya didrop jangan digunakan lagi sebagai variabel laten pelatihan. Variabel manifest $X$ pada kecerdasan emosi ada beberapa koefisien yang kurang dari 0.4 yakni D1, D2, D3, D5, D8, D9, D13, D14 sedangkan koefisien D4, D6, D7, D10, D11, D12 seluruhnya 
valid. Khusus untuk variabel yang kurang dari 0.4 sebaiknya didrop jangan digunakan lagi sebagai variabel laten kecerdasan emosi.

Berdasarkan hasil uji validitas (output completely standardized solution) setelah membuang yang tidak valid seluruh koefisien lambda-y $(\lambda y)$ seluruhnya bernilai lebih dar 0.6 maka disimpulkan variabel manifest $Y$ seluruhnya valid. Sementara untuk variabel manifest $X$ pada variabel $\mathrm{KEP}, \mathrm{BO}, \mathrm{PEL}$, dan KE telah memiliki loading factor $>0.4$, dimana hal ini menunjukkan bahwa semua indikator valid untuk mengukur konstruknya. Berdasarkan hasil perhitungan uji multikolinearitas yang dilakukan dengan melihat nilai korelasi antara variabel eksogen $<0.9$

Uji kecocokan model struktural dalam analisis SEM dilakukan dengan melihat beberapa kriteria Goodness of fit model seperti nilai Chi Square, probabilitas, df, GFI, AGFI, TLI, CFI, RMSEA dan RMR. Dalam penelitian ini, terpenuhinya goodness of fit akan difokuskan pada indikator goodness of fit yang berupa nilai probabilitas dan chi square yang tidak signifikan (probabilitas $>0.0 .5$ dan chi square $<(0.05$, df model)) menunujukkan bahwa model SEM yang diestimasi dengan data yang dianalisis memiliki matriks kovarian populasi sehingga dapat dipastikan memberikan gambaran kondisi populasi yang sebenarnya.

Berdasarkan hasil estimasi model struktural maka model telah memenuhi goodness of fit model yang baik pada indikator goodness of fit of RMSEA, diamana batas p-value $>0.05$ dan RMSEA $<0.08$ maka GOF sudah terpenuhi, disimpulkan model sudah fit dengan data, karena GOF dan RMSEA $=0.057<0.08$ walaupun $p$-value $=0.0000<0.05$.

Uji $T$ dimaksudkan untuk menguji apakah sebuah variabel berpengaruh signifikan terhadao variabel lainnya. Dasar pengambilan keputusan (nilai sig) $>0.05$ atau $\mathrm{t}$-tabel $<\mathrm{t}$ hitung $<\mathrm{t}$ table maka Ho tidak ditolak. Jika probabilitasnya (nilai sig) $<0.05$ atau $t$ hitung $<\mathrm{t}$ table atau $\mathrm{t}$ hitung $>\mathrm{t}$ tabel maka Ho ditolak, diterima $\mathrm{H} 1$.

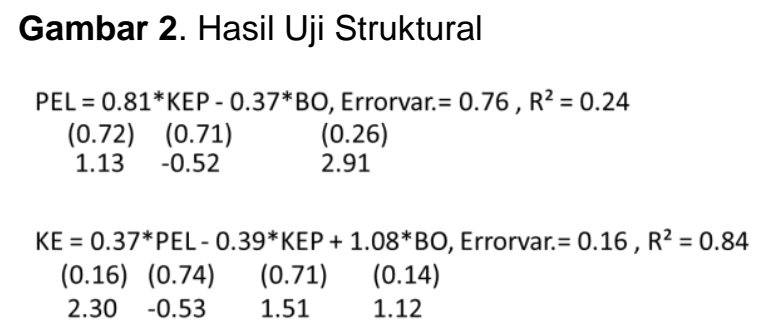

Berdasarkan persamaan struktural terlihat beberapa koefisien pengaruh langsung tidak signifikan diantaranya pengaruh langsung KEP terhadap PEL,BO terhadap PEL, KEP terhadap KE dan BO terhadap KE. 
Oleh karena itu peneliti melakukan reduce from euations untuk mendapatkan hasil yang lebih baik.

Gambar 3. The Modification Indicates Suggest

Reduced Form Equations

PEL $=0.81 * \mathrm{KEP}-0.37 * \mathrm{BO}$, Errorvar. $=0.76, \mathrm{R}^{2}=0.24$

(0.72) (0.71)

$1.13-0.52$

$\mathrm{KE}=-0.092 * \mathrm{KEP}+0.94 * \mathrm{BO}$, Errorvar. $=0.26, \mathrm{R}^{2}=0.74$

(0.61) (0.62)

$-0.15 \quad 1.53$

Reduce from equations, adalah prosedur untuk mengurangio lintasan jalur pada persamaan struktural. Dengan mereduksi bentuk persamaan ini diharapkan akan mampu memperbaiki koefisien jalur yang tidak signifikan. Berdasarkan informasi yang diberikan, terlihat jika melakukan modifikasi berdasarkan saran lisrel tersebut, maka seluruh koefisien jalur akan menjadi signifikan.

Gambar 4. Hasil Estimasi Model Struktural

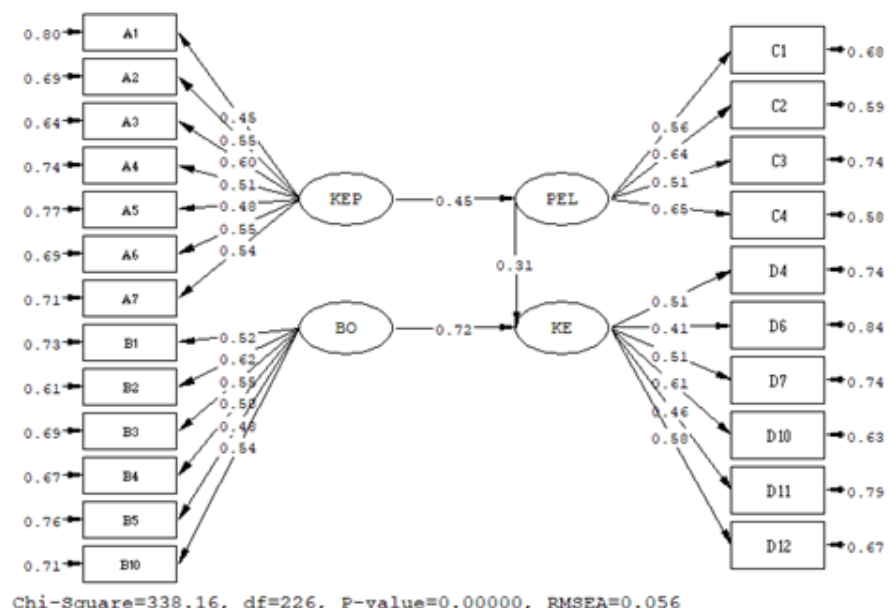

Berdasarkan kriteria Goodness of fit yang ada, dimana batas pvalue $>0.05$ dan RMSEA $<0.08$, maka GOF sudah dipenuhi, disimpulkan bahwa model sudah fit dengan data, karena RMSEA $=0.056<0.08$ walaupun $\mathrm{p}$-value $=0.00000<0.05$ sehingga model telah layak digunakan. 


\section{Variance Ectrated dan Construct Reliability}

Perhitungan construcr reliability dan variance ectrated dengan nilai standar evaluasi $\mathrm{CR} \geq 0.7, \mathrm{VE} \geq 0.5 \mathrm{p}>0.05, \lambda>0.4$ atau 0.5 dan $\mathrm{R} 2 \geq$ $0.7, \Sigma<0.51$ atau $51 \%$.

Tabel 1.1 Variance Ectrated \& Construct Reliability Variabel Kepemimpinan

\begin{tabular}{rrrrrr}
\hline KEP $\lambda$ & \multicolumn{2}{c}{$\lambda^{2}$} & & \multicolumn{1}{l}{$\mathrm{R}^{2}$} & Ket \\
\hline A1 & 0,45 & 0,2025 & 0,79 & 0.21 & Valid \\
A2 & 0,55 & 0,3025 & 0,70 & 0.30 & Valid \\
A3 & 0,59 & 0,3481 & 0,65 & 0.35 & Valid \\
A4 & 0,50 & 0,25 & 0,74 & 0.26 & Valid \\
A5 & 0,51 & 0,2601 & 0,75 & 0.25 & Valid \\
A6 & 0,53 & 0,2809 & 0,72 & 0.28 & Valid \\
A7 & 0,55 & 0,3025 & 0,70 & 0.30 & Valid \\
\hline$\Sigma$ & 4.06 & & & & \\
& $\mathrm{CR}=0,73$ & & & &
\end{tabular}

Tabel 1.2 Variance Ectrate \& Construct Reliability Variabel Budaya Organisasi

\begin{tabular}{cccccc}
\hline BO & $\lambda$ & \multicolumn{3}{c}{$\lambda^{2}$} & \multicolumn{2}{l}{$\mathrm{R}^{2}$} & Ket \\
\hline B1 & 0.52 & 0.2704 & 0.73 & 0.27 & Valid \\
B2 & 0.62 & 0.3844 & 0.62 & 0.38 & Valid \\
B3 & 0.55 & 0.3025 & 0.70 & 0.30 & Valid \\
B4 & 0.56 & 0.3136 & 0.69 & 0.31 & Valid \\
B5 & 0.47 & 0.2209 & 0.78 & 0.22 & Valid \\
B10 & 0.54 & 0.2916 & 0.71 & 0.29 & Valid \\
\hline$\Sigma$ & 4,27 & & & & \\
& $\mathrm{CR}=0,72$ & & & & \\
& $\mathrm{VE}=0,30$ & & & & \\
& & & & & \\
\hline
\end{tabular}


Tabel 1.3 Variance Ectrate \& Construct Reliability Variabel Pelatihan

\begin{tabular}{cccccc}
\hline PEL & $\lambda$ & $\lambda^{2}$ & $\varepsilon$ & $\mathrm{R}^{2}$ & Ket \\
\hline $\mathrm{C} 1$ & 0.54 & 0.2916 & 0.70 & 0.30 & Valid \\
$\mathrm{C} 2$ & 0.61 & 0.3721 & 0.63 & 0.37 & Valid \\
$\mathrm{C} 3$ & 0.51 & 0.2601 & 0.74 & 0.26 & Valid \\
$\mathrm{C} 4$ & 0.67 & 0.4487 & 0.55 & 0.45 & Valid \\
\hline$\Sigma$ & 2,8 & & & & \\
& $\mathrm{CR}=$ & 0,68 & & & \\
& $\mathrm{VE}=$ & 0,34 & & & \\
\end{tabular}

Tabel 1.4 Variance Ectrate \& Construct Reliability Kecerdasan Emosi

\begin{tabular}{cccccc}
\hline KE & $\lambda$ & \multicolumn{1}{l}{$\lambda^{2}$} & $\varepsilon$ & $\mathrm{R}^{2}$ & Ket \\
\hline $\mathrm{D} 4$ & 0.54 & 0.2916 & 0.71 & 0.29 & Valid \\
$\mathrm{D} 6$ & 0.42 & 0.1764 & 0.82 & 0.18 & Valid \\
$\mathrm{D} 7$ & 0.53 & 0.2809 & 0.72 & 0.28 & Valid \\
$\mathrm{D} 10$ & 0.53 & 0.2809 & 0.72 & 0.28 & Valid \\
$\mathrm{D} 11$ & 0.51 & 0.2601 & 0.74 & 0.26 & Valid \\
$\mathrm{D} 12$ & 0.61 & 0.3721 & 0.63 & 0.37 & Valid \\
\hline$\Sigma$ & 3.14 & & & & \\
& $\mathrm{CR}=$ & 0,69 & & & \\
\hline
\end{tabular}

Tabel 1.5 Ringkasan Estimasi

\begin{tabular}{ccccc}
\hline Model & $\lambda$ & $\mathrm{t}$ & $\mathrm{P}$ & $\mathrm{R}^{2}$ \\
\hline $\begin{array}{c}\text { Model PEL } \\
\mathrm{PEL} \leftarrow \text { KEP }\end{array}$ & 0,45 & 3,85 & 0,00 & 0,20 \\
$\quad$ Model KE & & & & \\
$\mathrm{KE} \longleftarrow$ PEL & 0,31 & 2,71 & 0,00 & 0,80 \\
$\mathrm{KE} \leftarrow$ BO & 0,72 & 5,23 & 0,00 & 0,80 \\
\hline
\end{tabular}


Tabel 1.6 Ringkasan Estimasi Pengaruh Langsung dan Tidak Langsung

\begin{tabular}{cccccc}
\hline \multirow{2}{*}{ Pengaruh antar Variabel } & \multicolumn{2}{c}{ Pengaruh } & \multirow{2}{*}{ Total } \\
\cline { 3 - 4 } & & Langsung & Tidak Langsung & \\
\hline KE & $\leftarrow$ & PEL & 0,31 & - & 0,31 \\
KE & KEP & - & $0,45 \times 0,31$ & 0,14 \\
KE $\longleftarrow$ & BO & 0,72 & - & 0,72 \\
\hline
\end{tabular}

Interpretasi hasil :

1. Tinggi rendahnya KE dipengaruhi secara positif oleh PEL sebesar 0.31 .

2. Tinggi rendahnya KE dipengaruhi secara positif oleh KEP melalui PEL sebesar 0,14.

3. Tinggi rendahnya KE dipengaruhi oleh $\mathrm{BO}$ sebesar 0,72 .

4. BO berpengaruh terbesar terhadap KE yaitu sebesar 0.72 terbesar kedua yaitu PEL 0.31 dan urutan ketiga atau terkecil yaitu 0.14.

\section{KOEFISIEN DETERMINASI $\left(\mathbf{R}^{2}\right)$}

Gambar 5: Hasil Koefisien Determinasi

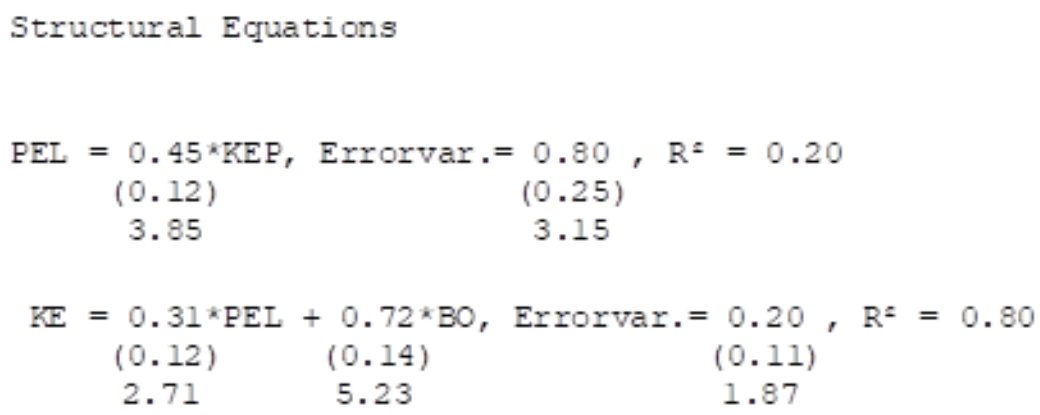

Berdasarkan hasil analisis pada tabel menunjukkan bahwa nilai koefisien determinasi (R2) variabel pelatihan adalah sebesar 0.20 , hal ini menunjukkan bahwa besar kontribusi yang diberikan variabel kepemimpinan sebesar $20 \%$ dipengaruhi oleh pelatihan, sedangkan variabel kecerdasan emosi sebesar 0.80 , hal ini menunjukkan bahwa besarnya kontribusi yang diberikan variabel pelatihan dan budaya organisasi sebesar $80 \%$ dipengaruhi oleh kecerdasan emosi.

\section{PEMBAHASAN}

Nilai $T$ value pengaruh variabel kepemimpinan terhadap pelatihan adalah sebesar 3,85 dengan koefisien jalur positif sebesar 0,45 . Oleh karena nilai T value yang diperoleh $>$ 1,96 dan koefisien jalur positif maka 
disimpulkan bahwa kepemimpinan berpengaruh positif dan signifikan terhadap pelatihan, hal ini menunjukkan bahwa baik kepemimipinan maka semakin baik pelatihan. Hal ini mendukung hipotesis 1 dalam penelitian ini sehingga hipotesis 1 diterima. Hasil penelitian ini sejalan dengan hasil penelitian I Wayan Sutya Edy, Kumara, I Wayan Mudiartha Utama (2016), hasil penelitiannya menunjukkan bahwa pelatihan berpengaruh positif dan signifikan terhadap kinerja dimediasi oleh kepemimpinan. Fadilla Astra, Jantje Mandet dan Very Londa juga mempunyai hasil yang sama yaitu kompetensi kepemimpinan dipengaruhi dan signifkan terhadap diklat atau pelatihan.

Nilai $T$ value pengaruh variabel budaya organisasi terhadap pelatihan adalah sebesar 1,12 dengan koefisien jalur positif sebesar 1,08 . Oleh karena nilai $T$ value yang diperoleh $<1,96$ dan koefisien jalur negatif maka disimpulkan bahwa budaya organisasi tidak berpengaruh dan tidak signifikan terhadap pelatihan, hal ini sejalan dengan penelitian yang dilakukan oleh Emilisa (2012) yang menyatakan bahwa budaya organisasi mempunyai pengaruh negatif terhadap learning organization akan tetapi pada penelitian yang dilakukan oleh Lita Regiana (2014) tidak memperkuat hasil penelitian ini, penelitian sebelumnya mengatakan budaya organisasi mempunyai berpengaruh terhadap pelatihan, akan tetapi pada penelitian ini menandakan bahwa budaya organisasi tidak berpengaruh terhadap pelatihan.

Nilai $T$ value pengaruh variabel kepemimpinan terhadap kecerdasan emosi adalah sebesar 1,51 dengan koefisien jalur positif sebesar 0,39. Oleh karena nilai $T$ value yang diperoleh $<1,96$ dan koefisien jalur negatif maka disimpulkan bahwa kepemimpinan tidak berpengaruh dan tidak signifikan terhadap kecerdasan emosi, hasil penelitan sejalan dengan penelitian dari Arindam Chatterjee, Atik Kulakli (2015) dan Alafta Rahma dan Fitri (2018), hasil penelitian menunjukkan bahwa kecerdasan emosi berpengaruh negative dan tidak signifikan terhadap gaya kepemimpinan.

Nilai $T$ value pengaruh variabel budaya organisasi terhadap kecerdasan emosi adalah sebesar 5.23 dengan koefisien jalur positif sebesar 0.72 Oleh karena nilai $T$ value yang diperoleh $>$ 1,96 dan koefisien jalur positif maka disimpulkan bahwa budaya organisai berpengaruh positif dan signifikan terhadap kecerdasan emosi, hal ini menunjukkan bahwa semakin baik budaya organisasi diberikan maka semakin baik tinggi kecerdasan emosi karyawan. Hal ini mendukung hipotesis 4 dalam penelitian ini sehingga hipotesis 4 diterima. al ini sejalan dengan penelitian yang dilakukan oleh Merlyn K (2016) dan Jadmiko (2017), hasil penelitiannya menunjukkan bahwa budaya organisasi mempunyai pengaruh yang tidak signifikan terhadap kecerdasan emosi.

Nilai $T$ value pengaruh variabel pelatihan terhadap kecerdasan emosi adalah sebesar 2,71 dengan koefisien jalur positif sebesar 0,31. Oleh karena nilai $T$ value yang diperoleh $>1,96$ dan koefisien jalur positif maka disimpulkan bahwa pelatihan berpengaruh positif dan signifikan terhadap 
kecerdasan emosi, hal ini menunjukkan bahwa semakin baik pelatihan diberikan maka semakin baik kecerdasan emosi karyawan. Hal ini mendukung hipotesis 5 dalam penelitian ini sehingga hipotesis 5 dapat diterima. Hasil penelitian ini sejalan dengan hasil penelitian Nur Chibtiyah, Djoko Santoso (2017) dan Hilda Rosa, Aditya Nanda dan Arif Tri (2017). hasil penelitian yang mereka lakukan sama-sama menunjukkan bahwa pelatihan berpengaruh positif dan signifikan terhadap kecerdasan emosi.

Nilai $T$ value pengaruh tidak langsung variabel kepemimpinan terhadap kecerdasan emosi adalah sebesar 0,15 dengan koefisien jalur positif sebesar -0,09. Oleh karena nilai $T$ value yang diperoleh $<1,96$ dan koefisien jalur negatif maka disimpulkan bahwa kepemimpinan terhadap kecerdasan emosi melalui pelatihan tidak memiliki pengaruh tidak langsung dan tidak signifikan, hal ini tidak sejalan dengan penelitian yang dilakukan oleh Anggia Sari dan Wulandari (2016), hasil penelitiannya mengatakan bahwa keceradasan emosi mempunyai pengaruh dan signifikan terhadap pelatihan, hasil penelitian yang sama juga pernah dilakukan oleh Honorata Ratnawati dan Mohammad Fasial Burhan (2018) yang mengahasilkan hal yang sama yaitu kecerdasan emosi memiliki pengaruh yang positif dan signifikan terhadap kepemimpinan.

Nilai $T$ value pengaruh tidak langsung variabel budaya organisasi terhadap kecerdasan emosi adalah sebesar 1,53 dengan koefisien jalur positif sebesar 0,94. Oleh karena nilai T value yang diperoleh $<1,96$ dan koefisien jalur negatif maka disimpulkan bahwa budaya organisasi terhadap kecerdasan emosi melalui pelatihan tidak memiliki pengaruh tidak langsung dan signifikan. Hasil penelitian ini sejalan dengan penelitian Rr Atika Wisnu Wardani, Ella Jauvani Sagala (2016) dan Purbo Jatmiko (2017), hasil penelitian mereka sama-sama menunjukkan bahwa budaya organisasi berpengaruh positif dan signifikan terhadap kecerdasan emosi.

\section{KESIMPULAN}

\section{Kesimpulan}

Berdasarkan data yang diperoleh dan dianalisis, dapat disimpulkan hal-hal sebagai berikut: 1) Kepemimpinan berpengaruh positif dan signifikan terhadap pelatihan pada PT. XYZ. Kepemimpinan yang baik akan membentuk pelatihan yang baik, begitu sebaliknya. 2) Budaya organisasi tidak berpengaruh positif dan signifikan terhadap pelatihan pada PT.XYZ. 3) Kepemimpinan terhadap budaya organisasi tidak berpengaruh positif dan signifikan pada PT. XYZ. 4) Budaya organisasi berpengaruh positif dan signifikan terhadap kecerdasan emosi pada $\mathrm{PT}$. $X Y Z$. Budaya organisasi yang tinggi akan mendorong terbentuknya kecerdasan yang baik, begitu sebaliknya. 5) Pelatihan berpengaruh positif dan signifikan terhadap kecerdasan emosi pada PT. XYZ. Pelatihan yang dilaksanakan dengan baik akan membentuk kecerdasan emosi yang baik, begitu sebaliknya. 6) Kepemimpinan tidak memiliki pengaruh tidak 
langsung dan tidak signifikan terhadap pelatihan pada PT. XYZ. 7) Budaya organisasi tidak memiliki pengaruh tidak langsung dan signifikan kecerdasan emosi pada PT. Supra Boga Lestari. Tbk unit operasional yaitu Ranch Market dan Farmers Market.

\section{Saran}

Berdasarkan hasil analisis pembahasan maka saran yang diberikan adalah: 1) Terus meningkatkan jumlah serta materi pelatihan yang sesuai dengan level jabatan karyawan, baik hard skill maupun soft skill karena dengan pelatihan dapat membentuk jiwa kepemimpinan dan kecerdasan emosi yang baik bagi karyawan. 2) Penerapan nilai budaya dan perilaku utama organisasi harus terus di kampanyekan dengan cara pembacaan visi, misi dan nilai-nilai perusahaan yang ada setiap pagi sebelum memulai pelatihan atau bekerja bagi karyawan, karena dengan penerapan nilai budaya organisasi akan mendorong terbentuknya kecerdasan emosi karyawan yang baik. 3) Perlu pelatihan bagi para karyawan dengan topik cara mencapai hasil kerja yang diinginkan dan budaya organisasi yang berfokus pada hasil, karena melihat hasil output aplikasi lisrel maka variabel dan indikator mengenai fokus pada hasil mendapatkan nilai terkecil sehingga perlu perhatian lebih dari perusahaan. 4) Dalam praktek pemberian materi pelatihan perlu lebih diperhatikan lagi, karena berdasarkan hasil output lisrel pelatihan sesuai usia mendapatkan nilai terkecil sehingga dapat diasumsikan bahwa pelatihan yang ada saat ini tidak sesuai dengan usia dan masa kerja karyawan. untuk itu, perlu di tinjau kembali. 5) Perlu diadakan lomba atau semacam kompetisi yang bertemakan kreativitas kepada karyawan operasional agar karyawan mampu mengekspreikan diri dalam sebuah kreativitas yang diberikan oleh perusahaan.

\section{DAFTAR PUTAKA}

Amna Ahmad Al Suwaidi and Mohammad Habibur Rahman.(2019). Organizational Culture, Leadership and Performance in Dubai Municipalit.

Arindam Chatterjee, Atik Kulakli.(2015). An Empirical Investigation of the relationship between Emotional Intelligence, Transsactional and Transformational Leadership Style in bangkin sector. Procedia Social and Behavioral Sciences 210 ( 2015 ) 291 - 300.

Asih Susanti dan Tjiptogoro Dinarjo Soehari (2019). Pengaruh Budaya Organisasi, Komitmen Organisasi dan Gaya Kepemimpinan terhadap Kinerja Karyawan. Jurnak Akademika Jurnal Teknologi Pendidikan, Volume 8, Nomor 02, 2019 
Ayse Turksoya, Burcak Keskinb, Canan Duranc.(2014). Examining Emotional Intelligence and Leadership Skills of Trainers. Procedia Social and Behavioral Sciences 185 ( 2015 ) $117-122$.

Budiono, Udik, Budi Wibowo.(2014). Pengaruh Komunikasi Organisasi, Kecerdasan Emosi dan Pengambilan Keputusan Terhadap Implementasi Peran Kepemimpinan Kepala SD. Jurnal Akutabilitas Manajemen Pendidikan Volume 2, Nomor 2, 2014.

Claudia Madali, Eka Desy Purnama.(2014). Pengaruh Emotional Quotient (EQ) terhadap Gaya Kepemimpinan, Stress Kerja dan Kepuasan Kerja, dalam meningkatkan Kinerja Karyawan di PT. Karya Teknik Makmur. Jurnal Manajemen \& Bisnis, Vol. 9, No. 1 Juni 2014.

Deepika Dabke.(2016). Impact of Leader's Emotional Intelligence and Transformational Behavior on Perceived Leadership Effectiveness: A Multiple Source View. Management Studies and Research SAGE Publications.

Dessler, Gary. 2010 . Manajemen Sumber Daya Manusia (edisi kesepuluh). Jakarta Barat: PT Indeks.

Diah Amalia, Muhammad Ramadhan.(2019). Pengaruh Kecerdasan Emosional dan Kecerdasan Spiritual. Journal of Applied Managerial Accounting. Vol. 3, No. 1, March 2019, Page 121-134.

Emily M Potter, Temitope Egbelakin, Robyn Phipps, Behrooz Balaei.(2016). Emotional intelligence and transformational leadership behaviours of construction project managers.

Faycal Boukamcha.(2019). The effect of transformational leadership on corporate entrepreneurship in Tunisian SMEs. The current issue and full text archive of this journal is available on Emerald Insight at: emeraldinsight.com/0143-7739.

Goleman, Daniel. 2009. Kecerdasan Emosional : Mengapa El lebih penting daripada IQ. Jakarta : PT. Gramedia Pustaka Utama.

Hersey, Paul dan Kenneth. H. Blanchard, Manajemen Perilaku Organisasi : Pendayagunaan Sumber Daya Manusia, Terjemahan Agus Dharma, Erlangga, Jakarta, 2000

Mangkunegara, A.A. Anwar Prabu. (2013). Manajemen Sumber Daya Manusia Perusahaan.Bandung:PT.Remaja Rosdakarya. 
Rizal Abdul, Farida Elmi (2017). "Pengaruh gaya kepemimpinan transformasional, disiplin kerja dan penempatan kerja terhadap kinerja"

Robbins, Stephen P \& Judge, Timothy A. 2013. Organizational Behavior Edition15. New Jersey: Pearson Education

Sigit Susatmoko.(2017). Pengaruh Gaya Kepemimpinan, Pemahaman Good Governance, Konflik Peran Terhadap Kinerja Auditor dengan Kecerdasan Emosional Sebagai Variabel Pemoderasi.

Sudaryono. (2017). Pengantar Manajemen. Yogyakarta: CAPS.

Sugiyono. 2010. Metode Penelitian Pendidikan Pendekatan Kuantitatif, kualitatif, dan R\&D. Bandung: Alfabeta

Sugiyono. 2013. Metode Penelitian Pendidikan Pendekatan Kuantitatif, Kualitatif, dan R\&D. Bandung: Alfabeta

Usman Effendi, Asas Manajemen, Jakarta; PT Raja Grafindo,2011,h.188189

Veithzal Rivai. 2014. Manajemen Sumber Daya Manusia untuk Perusahaan, Edisi ke 6, PT. Raja Grafindo Persada, Depok, 16956.

ZhenShao.(2019). Interaction Effect of Strategic Leadership Behavior and Organizational culture on Business Strategic Alignment and Enterprise System Assimilation.International journal of information management 44 (2019) 96-108

Zhidong Li Bindu Gupta mark Loon Gian Casimir.(2016). ,"Combinative aspects of leadership style and emotional intelligence", Leadership \& Organization Development Journal, Vol. 37 